\title{
Performance Enhancement of WDM-PON FTTH Network by Using Decision Feedback and Feed forward Equalizations
}

\author{
Sooraj Parkash ${ }^{*}$, Anurag Sharma ${ }^{1}$, Manoj Kumar ${ }^{2}$ and Harsukhpreet Singh $^{3}$ \\ *, 1, 2, 3 CT Institute of Technology \& Research, Jalandhar, Punjab, India \\ soorajparkash879@gmail.com*,er.anurags@gmail.com ${ }^{1}$
}

\begin{abstract}
In this paper, Decision Feedback Equalization (DFE) and Feed forward Equalization $(F F E)$ based on minimum mean square error optimization has been employed to improve the performance of 32 channels, gigabit capacity WDM-PON network. An optical line terminal $(O L T)$ installed at the transmitter end which continuous transmit 32 channels having different colors (wavelengths) of 20GB/s data rate, which is multiplexed by optical multiplexer and transmit through standard single mode fiber (SMF) having length 40km. A link design for 1:64 optical splitters is used as Passive Optical Network (PON) element which creates communication between OLT to different end users. It is observed that FFE and DFE significantly reduce BER by $1.0798 e^{-010}, 1.1556 e^{-011}$, $1.2960 e^{-010}$ and $8.8979 e^{-009}$ at four different wavelengths $1550 \mathrm{~nm}, 1559.6 \mathrm{~nm}, 1562.8 \mathrm{~nm}$ and $1574.8 \mathrm{~nm}$ by using NRZ (non return zero) modulation format at 20GB/s for 64 users having $40 \mathrm{~km}$ fiber length respectively. Sharp increase in BER $2.6916 e^{-002}, 4.6519 e^{-002}$, $3.8804 e^{-001}$ and $5.1570 e^{-002}$ occurs if data rate increases up to $25 \mathrm{~GB} / \mathrm{s}$.
\end{abstract}

Keywords: - WDM-PON, OLT, ONU, NRZ, BER, FFE, DFE

\section{Introduction}

Today, the growth of the internet and broadband services are increasing very sharply. To complete these demands WDM-PON (Wavelength Division Multiplexing Passive Optical Network) is one of the most promising approaches [6]. Fiber to the home networks are used for deployed to increase the bandwidth and provide more services to the users [2]. These technologies are based on TDM (Time division multiplexing) which provide data in $100 \mathrm{Mbps}$ per single users. Compared with TDM-PON WDM-PON is not suitable for transmission of video broadcasting intrinsically. The TDM-PON transmits the downstream to all subscribers employing optical splitter, while WDM-PON operated in point to point $(\mathrm{P} 2 \mathrm{P})$ model each subscriber its dedicated wave length by AWG [14].Currently WDM (Wavelength Division Multiplexing) technique being used for higher data rates. WDM PON is providing low power loss, more bandwidth and better privacy [13]. In WDM-PON the number of different wavelengths (Laser array) on transmitting side is multiplexed by the optical multiplexer and transmit over fiber. On receiving side an optical splitter is used to split the signal power in equal amount and distribute to each ONU (Optical Network Unit). Each ONU receive the same multiplexed signal which having same Bit Error Rate (BER). Recently long reach 10 GB/s WDM PON system has being demonstrated using coherent detection [1]. Core networks are usually based on mesh topology with WDM [3].Traditional WDM PON are allocated a separate pair of dedicated upstream and downstream channel to each user for delivering of a symmetric $1 \mathrm{~GB} / \mathrm{s}$ or more [5]. WDM is selected by FSAN as a primary solution for next generation NG-PON2 [4]. NG-PON2 at least supports data rate up to 40G/bits for downstream. In a WDM PON configuration, each ONU (Optical Network Unit) receives the throughput supported by the wavelength assigned to it. Wavelength tunable VCSELs arrays are used for the downlink in a network WDM-PON 
[7]. WDM-PON with colorless ONU has been use for future high capacity broadband access networks due to its cost effectiveness and flexibility [8, 17].The RSOA (Regenerated semiconductor optical amplifier) ONU advantageous for WDM-PON due to its compact size and low power consumption [8]. WDM-PON system has multiple transmitters' lasers operating at different wavelengths which need to be wavelength selective for each channel and operate at specific wavelength [11]. The WDM-PON networks work as backbone networks for broadband services. Using WDM-PON networks we can transmits the data rate $400 \mathrm{~GB} / \mathrm{s}$ up to $5 \mathrm{Km}$ with efficient Bit Error Rate (BER) [15]. For high transmission capacity leads to the creation of new modulation formats. Chirped RZ (CRZ) is a special type of return-to-zero (RZ) modulation implemented by the pre-chirp on Return Zero pulses. This modulation format is usually used in long-haul transmission links. Carry-err-suppressed RZ modulation is a recent modulation format for high-capacity transmission links [16].

K.P Kaur et al. [11] have reviewed a simple and cost effective spectrum WDM-PON architecture for 32 users. The feasibility of network is analyzed using BER analysis. The architecture survives up to $150+20 \mathrm{Km}$ fiber length having BER for each channel is 10-9. K.P Kaur et al. [12] have reviewed that performance effect of 40Gbps WDM-PON is analyzed using different receiver filters. The data rate and channel spacing are taken as $10 \mathrm{~GB} / \mathrm{s}$ per channel and $100 \mathrm{GHz}$, respectively. We also reviewed that from other filters which is to be investigated Bessel filter is the best one for WDM-PON network by the obtained BER and Q factor values. Kartiwa et al. [10] have reviewed that use of millimeter wave signal by using optical carrier suppression method having 20G/bits WDM-OFDM-PON in 20Km fiber length. The transmission is based on RSOA. RS.Kaler et al. [9] have reviewed that transmission of triple services using GEPON architecture using 1:8 splitter having data rate $10 \mathrm{~GB} / \mathrm{s}$ with $15 \mathrm{Km}$ fiber length. Sharp increase in BER occurs if fiber length increases beyond $15 \mathrm{~km}$. A. Sharma et al. [18] have reviewed that simulation of 100 ONU's at $5 \mathrm{Gbps}$ with fiber length $20 \mathrm{~km}$ and BER value is obtained $2.3415 \mathrm{e}-010$ by using CRZ modulation format. System is unstable if more number of users accommodates and fiber length increased more than $20 \mathrm{~km}$. Mu et al. [16] have reviewed that designed a WDM network and compared different modulation formats such as NRZ, RZ and CRZ systems and observed that CRZ modulation format is the best suited for the network because of the chirping effect present in this format, which reduces dispersion.

The work in this paper is enhancement of previous work, a WDM-PON system is designed for at 20x32Gbps data rate in downstream with $40 \mathrm{~km}$ fiber length for 64 subscribers. This paper comprises of three sections, the first section presents the introduction of WDM-PON technology along with the literature review. The second section presents the simulation setup for WDM-PON architecture. An optical line terminal (OLT) is installed at the transmitter end which transmit continuous 32 channels having different wavelength signal with $0.8 \mathrm{~nm}$ spacing of $20 \mathrm{~GB} / \mathrm{s}$ which is multiplexed by optical multiplexer and transmit through single mode fiber (SMF). ). At the receiving end ONUs have PIN detectors which convert the optical signal into electrical signal EDC technique is used for decreasing the value of BER. In third section simulations are performed for NRZ modulation formats on WDM-PON networks. The simulation work report of BER are obtained $1.0798 \mathrm{e}^{-010}, 1.1556 \mathrm{e}^{-011}, 1.2960 \mathrm{e}^{-010}$ and $8.8979 \mathrm{e}^{-009}$ at four different wavelengths $1550 \mathrm{~nm}, 1559.6 \mathrm{~nm}, 1562.8 \mathrm{~nm}$ and $1574.8 \mathrm{~nm}$ for NRZ modulation format at $20 \mathrm{~GB} / \mathrm{s}$ for 64 users with $40 \mathrm{~km}$ fiber length respectively.

\section{Simulation Setup}

Wavelength division multiplexing passive optical network (WDM-PON) which provide high bandwidth per user and support multiple channels. Indeed work out in this paper demonstrate a high speed WDM network. Figure 1 presents the general 
architecture of simulation system, including optical line terminal, which communicate with 64 ONU's (end users) via standard single mode fiber of $40 \mathrm{~km}$ length. In this simulation set up a central office which transmits whole data rate 640Gbps. The OLT (Optical Line Terminal) continuous transmit 32 channels, each channel has data rate of 20Gbps. Figure 2(a) shows the OLT component of WDM-PON network. OLT consist of PRBS generator, electrical pulse generator, $\mathrm{CW}$ laser array, M-Z modulator, optical power normalizes and optical mux. The PRBS generator which produce continuous stream of bits in digital form in 0 or 1's with pattern length 9 bits and 7 points per bit. The output of PRBS generator is goes into the electrical generator. The electrical generator applies the NRZ modulation format on data which is generated by the PRBS generator, now the output of electrical generator goes to MZ modulator. The output signal of laser in form of color (wavelength) goes in machzehnder modulator (MZ). The output of MZ modulator goes into the optical power normalize having Avg. output power -3.0dB. In this simulation setup we used 32 channels each channel having different wavelength. Channel 1 has wavelength is $1550 \mathrm{~nm}$, channel 13 has wavelength $1559.6 \mathrm{~nm}$, channel 17 has wavelength $1562.8 \mathrm{~nm}$ and channel 32 have wavelength $1574.8 \mathrm{~nm}$. These wavelengths are multiplexed by the optical multiplexer and transmit through the standard single mode fiber (SMF). The length of the fiber is $40 \mathrm{~km}$ and having loss is $025 \mathrm{~dB}$. The type of fiber is a G.652 SMF. The $32 \mathrm{WDM}$ channels were separated by $100 \mathrm{GHz}(0.8 \mathrm{~nm})$ at standard International Telecommunication Union (ITU). SMF is inserted in to the optical splitter.

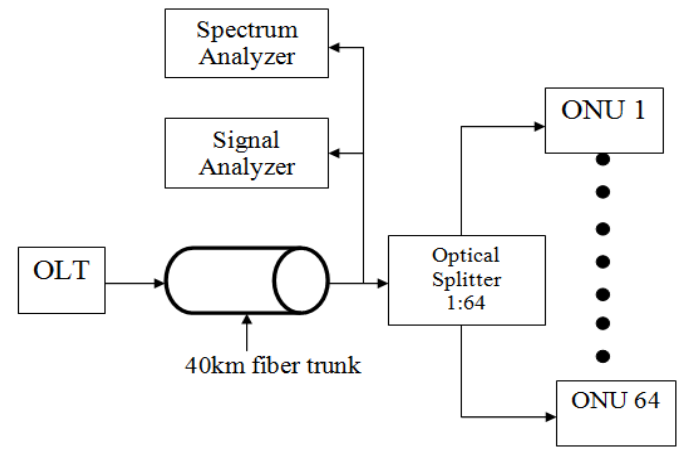

Figure 1. Block Diagram of WDM-PON Architecture for 64 Users

(a)

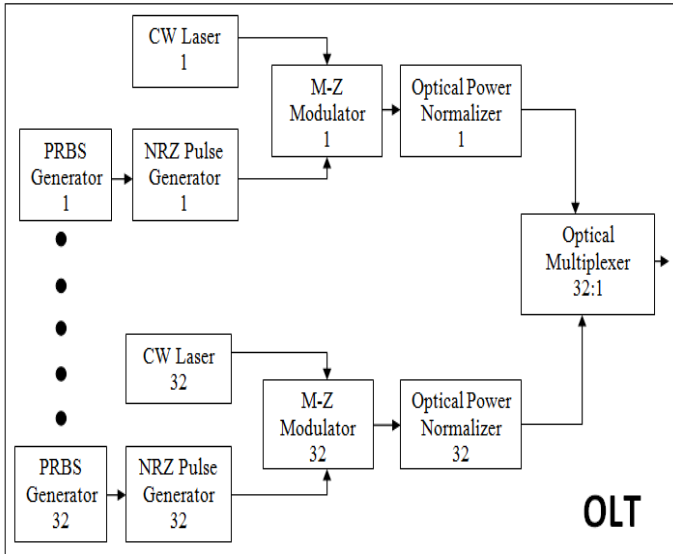

(b)

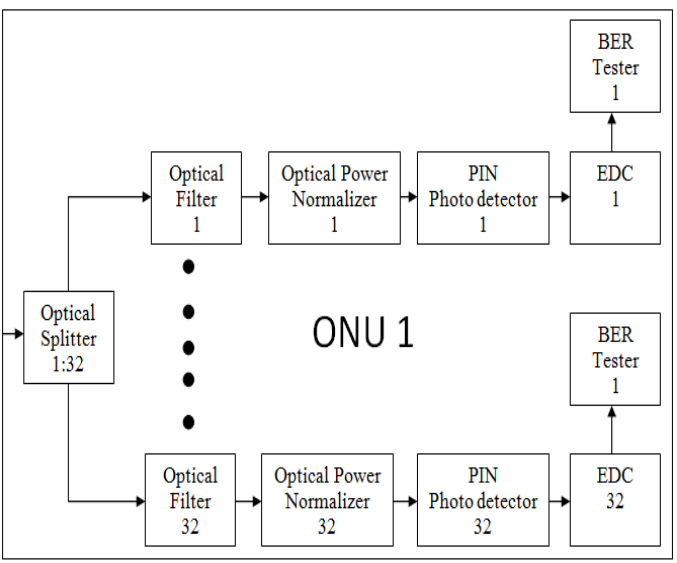

Figure 2. (a) OLT Components for WDM-PON based Architecture (b) ONT Components for WDM-PON based Architecture 
A link design for 1:64 optical splitters is used as Passive Optical Network (PON) element which creates communication between OLT to different users. An optical splitter is split the multiplexed signal which is multiplexed by optical multiplexer and received by each end user. The signal received by each user have equal power and Bit Error Rate (BER) ratio. Figure 2(b) shows the ONT component of WDM-PON network. On the receiving side optical network terminal data receiver configured with optical filters, PIN receiver and EDC (electronic dispersion compensation) and BER Tester. Optical filter filtered the optical signal as per input wavelength. The optical power normalizes having Avg. down receiving power $15 \mathrm{~dB}$ which helps decreasing the value of BER. On receiving side convert the data again in the original form, we use a high sensitivity receiver or detector which performs both the function, the first one is to detect whether data or voice is and again converted in the form of the electrical signal. The performance of the proposed link with application of Optical Dispersion Compensation has been considered. Even after Optical Dispersion compensation, significant inter symbol interference (ISI) is observed in the signal after the photo receiver which limits the performance and reach of the system. Electronic Dispersion Compensation (EDC) is an effective tool to negate the dispersion in electrical domain. As shown in figure 2, MMSE based EDC is applied after the receiver to further enhance the performance of the system. EDC technique used is based on feed forward equalization (FFE) and decision feedback equalization (DFE). Using digital signal processing, the performance of FFE/DFE has been optimized on the basis of feed forward and feed backward taps. The But as we know that data is transmitted in the digital domain or also in the light pulses so in transmission on the fiber such type of noise also produced e.g. inter symbol interference, noise so in the effect of such things error should be occurred. So to measure the error we applied an instrument called BER Tester.

\section{Results and Discussion}

The work in this paper demonstrates high speed WDM-PON network. In WDM-PON multiplexing of 32 channels which having different wavelengths and each channel is transmitted $20 \mathrm{~GB} / \mathrm{s}$ data rate. The $32 \mathrm{WDM}$ channels were separated by $100 \mathrm{GHz}$ $(0.8 \mathrm{~nm})$ at standard International Telecommunication Union (ITU). Table 1 shows the BER for various subscribers for $20 \mathrm{~GB} / \mathrm{s}$ at $40 \mathrm{~km}$ fiber length. For example the BER for 8 users are obtained $9.4974 \mathrm{e}^{-023}, 1.6229 \mathrm{e}^{-028}, 1.1035 \mathrm{e}^{-028}$ and $3.2600 \mathrm{e}^{-038}$ for $20 \mathrm{~GB} / \mathrm{s}$ with $40 \mathrm{~km}$ fiber length at $1550 \mathrm{~nm}, 1559.6 \mathrm{~nm}, 1562.8 \mathrm{~nm}$ and $1574.8 \mathrm{~nm}$ wavelengths. Similarly we observed value of BER for 64 users are $1.0798 \mathrm{e}^{-010}, 1.1556 \mathrm{e}^{-011}, 1.2960 \mathrm{e}^{-010}$ and $8.8979 \mathrm{e}^{-009}$ for $20 \mathrm{~GB} / \mathrm{s}$ at $40 \mathrm{~km}$ fiber length at $1550 \mathrm{~nm}, 1559.6 \mathrm{~nm}, 1562.8 \mathrm{~nm}$ and $1574.8 \mathrm{~nm}$ wavelengths. We analyzed that if number of user increases the BER is also increases.

Table 1. BER for Various Users for $20 \mathrm{~GB} / \mathrm{s}$ at $40 \mathrm{~km}$ Fiber Length

\begin{tabular}{|c|c|c|c|c|}
\hline \multirow{2}{*}{ Users } & \multicolumn{4}{|c|}{ Wavelengths } \\
\cline { 2 - 5 } & $\chi_{1}=1550 \mathrm{~nm}$ & $\chi_{13}=1559.6 \mathrm{~nm}$ & $\chi_{17}=1562.8 \mathrm{~nm}$ & $\chi_{32}=1574.8 \mathrm{~nm}$ \\
\cline { 2 - 5 } & BER & BER & BER & BER \\
\hline 8 & $9.4974 \mathrm{e}^{-023}$ & $1.6229 \mathrm{e}^{-028}$ & $1.1035 \mathrm{e}^{-028}$ & $3.2600 \mathrm{e}^{-038}$ \\
\hline 16 & $1.8074 \mathrm{e}^{-019}$ & $2.8924 \mathrm{e}^{-021}$ & $3.2554 \mathrm{e}^{-023}$ & $5.6232 \mathrm{e}^{-030}$ \\
\hline 32 & $3.0112 \mathrm{e}^{-016}$ & $2.7576 \mathrm{e}^{-018}$ & $4.6659 \mathrm{e}^{-019}$ & $6.6065 \mathrm{e}^{-021}$ \\
\hline 48 & $1.3493 \mathrm{e}^{-013}$ & $2.0547 \mathrm{e}^{-014}$ & $1.3713 \mathrm{e}^{-016}$ & $1.0149 \mathrm{e}^{-015}$ \\
\hline 64 & $1.0798 \mathrm{e}^{-010}$ & $1.1556 \mathrm{e}^{-011}$ & $1.2960 \mathrm{e}^{-010}$ & $8.8979 \mathrm{e}^{-009}$ \\
\hline
\end{tabular}

Figure 3 Represents the BER versus the users. Here we see that if we increase data rate, BER increases sharply but it accommodates less users and if we decrease the data rate, BER decreases and more number of users get accommodated. For example for data 
rate of $10 \mathrm{~GB} / \mathrm{s}$ for 64 users we have BER values are $1.8513 \mathrm{e}^{-071}, 1.6401 \mathrm{e}^{-063}, 6.6983 \mathrm{e}^{-063}$ and $2.6034 \mathrm{e}^{-74}$ Similarly, for $15 \mathrm{~GB} / \mathrm{s}$ system at 64 users we have BER values are $2.3479 \mathrm{e}^{-039}, 1.1941 \mathrm{e}^{-029}, 4.6645 \mathrm{e}^{-029}$ and $1.3433 \mathrm{e}^{-034}$. Similarly, for $20 \mathrm{~GB} / \mathrm{s}$ system then we have BER values are $1.0798 \mathrm{e}^{-010}, 1.1556 \mathrm{e}^{-011}, 1.2960 \mathrm{e}^{-010}$ and $8.8979 \mathrm{e}^{-009}$ at $1550 \mathrm{~nm}$, $1559.6 \mathrm{~nm}, 1562.8 \mathrm{~nm}$ and $1574.8 \mathrm{~nm}$ wavelengths with $40 \mathrm{~km}$ fiber length. If we further increase data rate up to $25 \mathrm{~GB} / \mathrm{s}$ then we observe a sudden increase in BER value of $2.6916 \mathrm{e}^{-002}, 4.6519 \mathrm{e}^{-002}, 3.8804 \mathrm{e}^{-001}$ and $5.1570 \mathrm{e}^{-002}$ at $1550 \mathrm{~nm}, 1559.6 \mathrm{~nm}, 1562.8 \mathrm{~nm}$ and $1574.8 \mathrm{~nm}$ wavelengths with $40 \mathrm{~km}$ fiber length. So there is a trade-off between bit error rate and data rate of system.

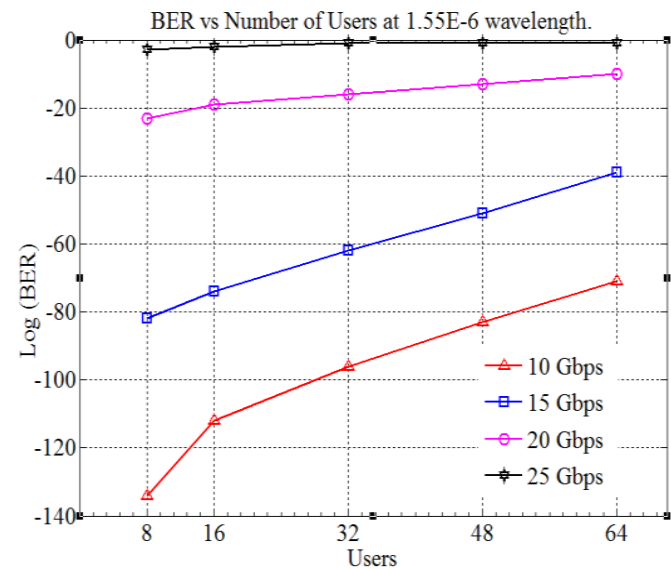

(a)

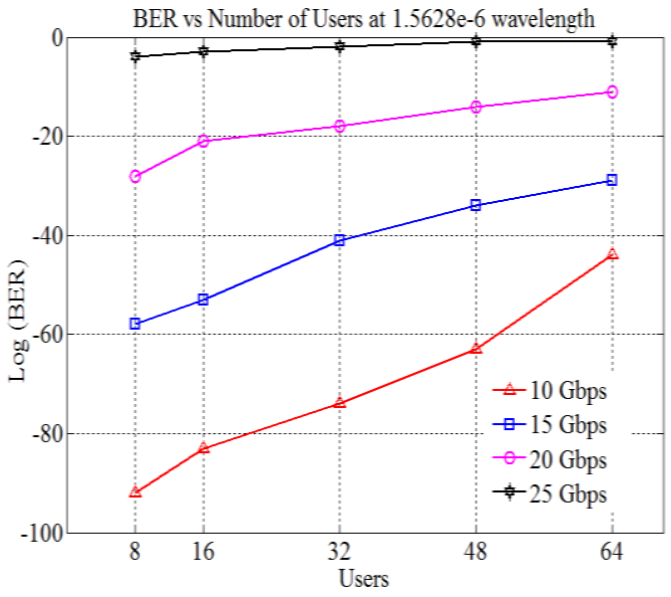

(b)

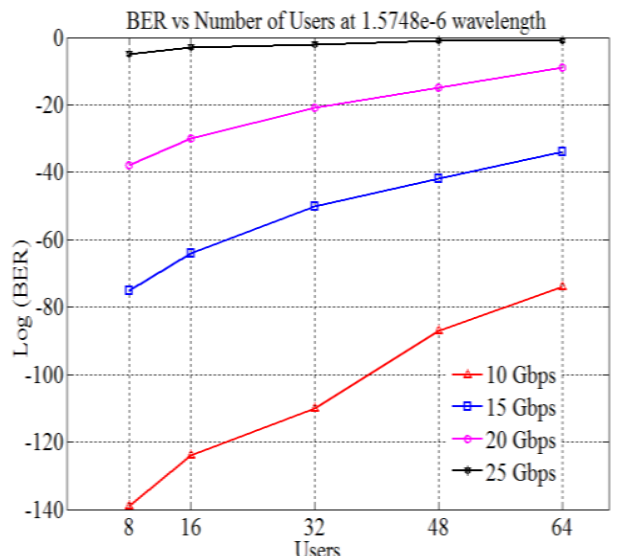

(c)

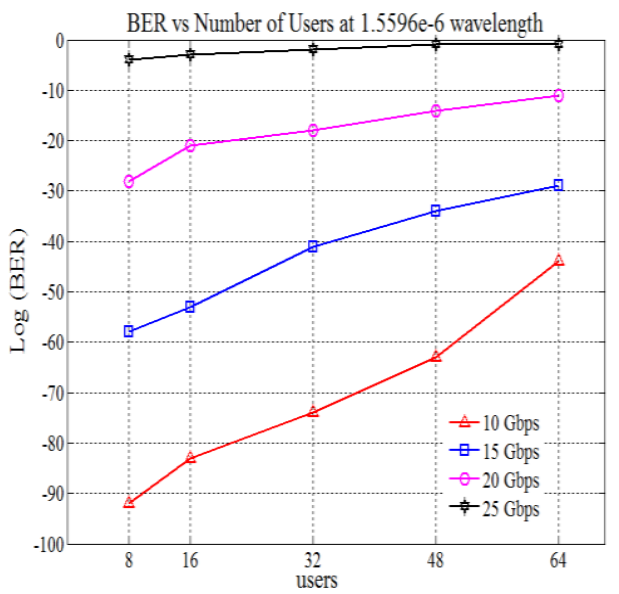

(d)

Figure 3. (a) Comparison of system BER at various data rates at $40 \mathrm{~km}$ fiber length for 1550nm; (b) Comparison of system BER at various data rates at $40 \mathrm{~km}$ fiber length for $1562.8 \mathrm{~nm}$; (c) Comparison of system BER at various data rates at $40 \mathrm{~km}$ fiber length for $1574.8 \mathrm{~nm}$; (d) Comparison of system BER at various data rates at $40 \mathrm{~km}$ fiber length for $1559.6 \mathrm{~nm}$

Figure 4 (a) (b) (c) (d) shows the variation of distance vs. BER for various users. It is seen that if we increase distance, Bit Error Rate increases very sharply. For example, for 8 users at $40 \mathrm{~km}$ for $20 \mathrm{~GB} / \mathrm{s}$ data rate we received BER values are $9.4974 \mathrm{e}^{-023}, 1.9413 \mathrm{e}^{-}$ ${ }^{052}, 6.5090 \mathrm{e}^{-050}$ and $1.8396 \mathrm{e}^{-057}$ then for same users and data rate at distance of $80 \mathrm{~km}$, BER values are $1.2391 \mathrm{e}^{-005}, 5.2366 \mathrm{e}^{-005}, 3.2028 \mathrm{e}^{-005}$ and $5.0060 \mathrm{e}^{-006}$ at $1550 \mathrm{~nm}$, $1559.6 \mathrm{~nm}, 1562.8 \mathrm{~nm}$ and $1574.8 \mathrm{~nm}$ wavelengths. Similarly, for 64 users with $40 \mathrm{~km}$ fiber length for data rate of $20 \mathrm{~GB} / \mathrm{s}$ we obtained BER values are $1.0798 \mathrm{e}^{-010}, 1.1556 \mathrm{e}^{-011}$, 
$1.2960 \mathrm{e}^{-010}$ and $8.8979 \mathrm{e}^{-009}$ for same users and data rate at $80 \mathrm{~km}$, BER values are $1.3996 \mathrm{e}^{-001}, 3.7052 \mathrm{e}^{-001}, 3.8804 \mathrm{e}^{-001}$ and $7.7576 \mathrm{e}^{-002}$ at $1550 \mathrm{~nm}, 1559.6 \mathrm{~nm}, 1562.8 \mathrm{~nm}$ and $1574.8 \mathrm{~nm}$ wavelengths. This proves that there is a tradeoff between number of users, distance and BER. Dispersion is major factor in long haul transmission. Broadening of pulses is called dispersion. Figure 5 depicts the eye diagram for in case of 64 users at varying fiber lengths. Eye diagram shows the width and height of the eye opening. Thus the width and height of the eye opening is large which means that reception of the signal is very much clear. The width of eye opening defines the time interval over which received signal can be sampled without interference and distortion. The height of eye opening shows the noise margin of the signal. Basically, the opening of eye at $20 \mathrm{~GB} / \mathrm{s}$ is more open at $40 \mathrm{~km}$ fiber length rather than $80 \mathrm{~km}$ fiber length because the BER value of 64 users at $40 \mathrm{~km}$ fiber length is obtained $1.0798 \mathrm{e}^{-010}$ and BER value at $80 \mathrm{~km}$ fiber length is $1.3996 \mathrm{e}^{-001}$ at $1.55 \mathrm{e}-006$ wavelength, so it means if we increased fiber length opening of eye is less and dispersion is more.

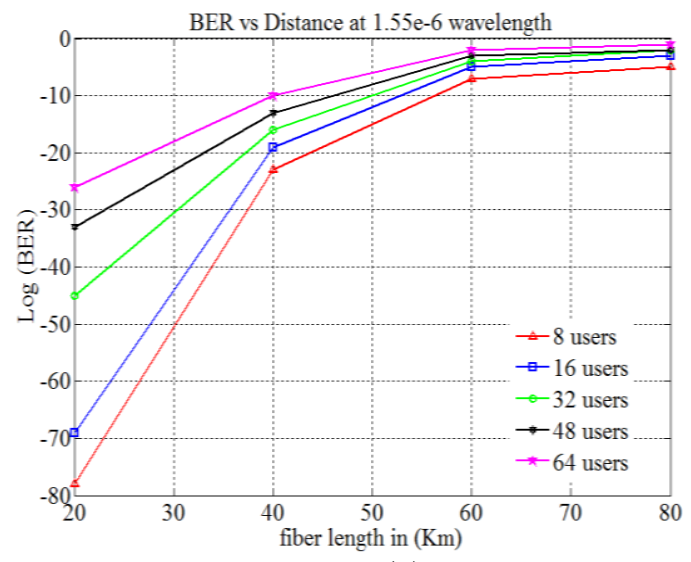

(a)

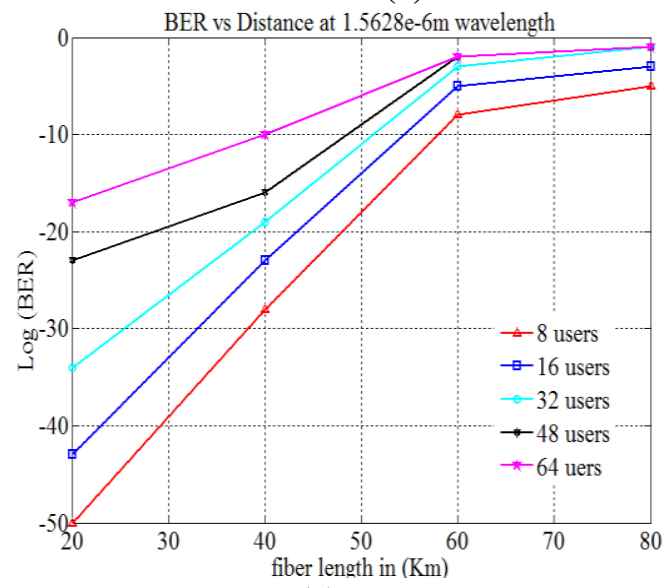

(c)

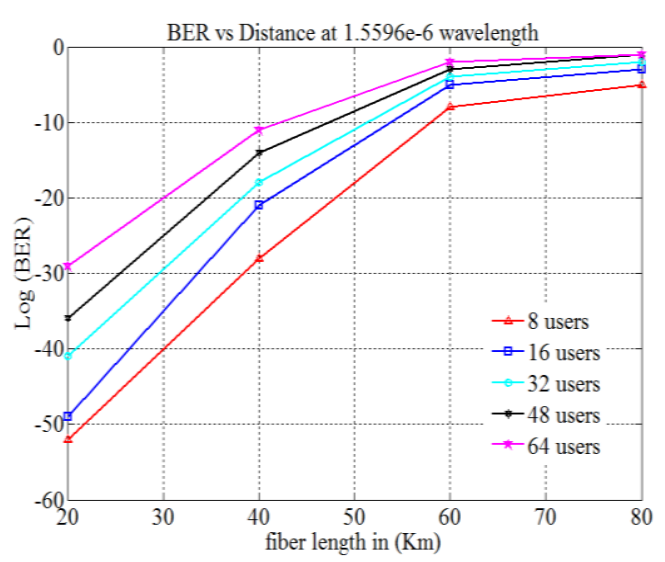

(b)

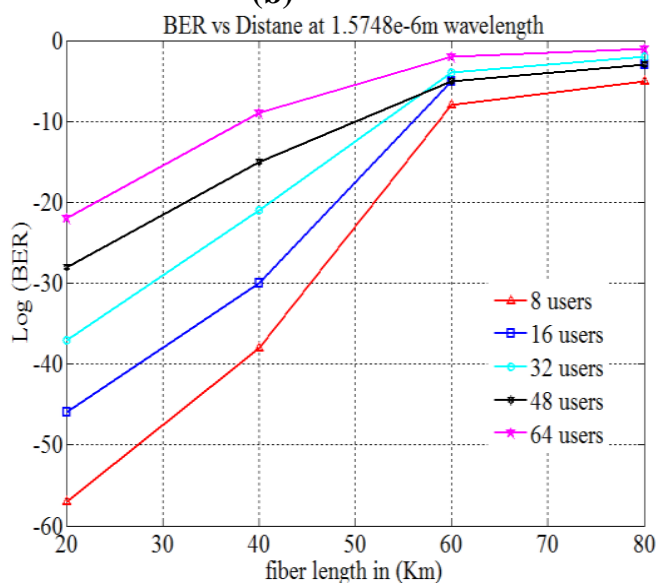

(d)

Figure 4. (a) BER vs. distance for $20 \mathrm{~GB} / \mathrm{s}$ data rate at $40 \mathrm{~km}$ fiber length for $1550 \mathrm{~nm}$ (b) BER vs. distance for $20 \mathrm{~GB} / \mathrm{s}$ data rate at $40 \mathrm{~km}$ fiber length for $1559.6 \mathrm{~nm}$ (c) BER vs. distance for $20 \mathrm{~GB} / \mathrm{s}$ data rate at $40 \mathrm{~km}$ fiber length for $1562.8 \mathrm{~nm}$ (d) BER vs. distance for $20 \mathrm{~GB} / \mathrm{s}$ data rate at $40 \mathrm{~km}$ fiber length at $1574.8 \mathrm{~nm}$ 


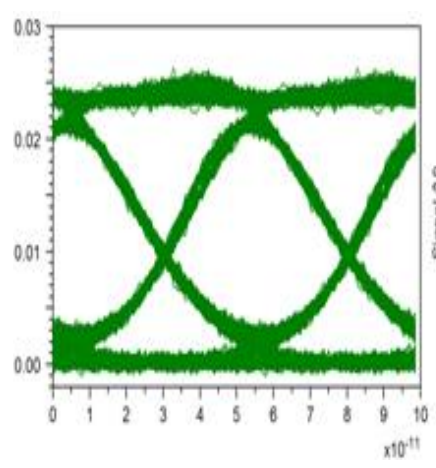

(a)

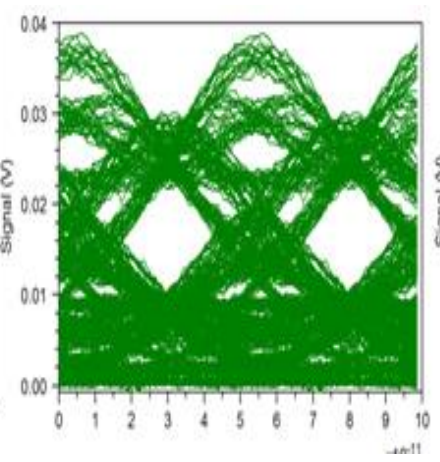

(b)

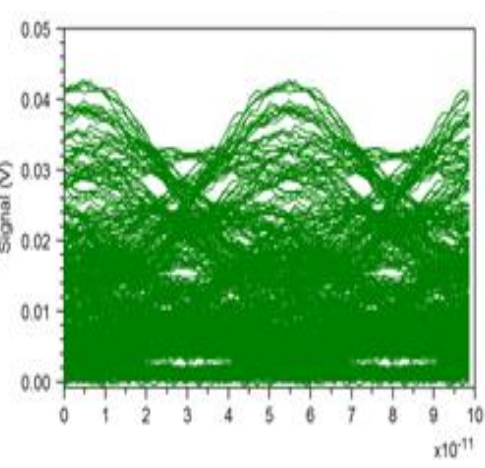

(c)

Figure 5. (a) Eye diagram for 64 users for $20 \mathrm{~GB} / \mathrm{s}$ at $40 \mathrm{~km}$ at $1550 \mathrm{~nm}$, (b) Eye diagram for 64 user for $20 \mathrm{~GB} / \mathrm{s}$ at $60 \mathrm{~km}$ at $1550 \mathrm{~nm}$ and (c) Eye diagram for 64 user for $20 \mathrm{~GB} / \mathrm{s}$ at $80 \mathrm{~km}$ at $1550 \mathrm{~nm}$

\section{Conclusion}

This implementation simulated an optimized WDM-PON based FTTH access network to provide residential subscribers with data services in $\mathrm{GB} / \mathrm{s}$. We described the requirements of WDM-PON access network with considerations of services and PON specific layered functions. To satisfy those requirements, we simulated an optimized architecture and describe the detailed functions of major elements. Today WDM-PON is a driver for the development of advances optoelectronics technologies, and the great volume in production of optical modules will also accelerate the reduction in cost. In real life WDM-PON are used in FTTH networks. FTTC (fiber to the curb), FTTB (fiber to the building). WDM-PON networks are act as backbone networks in E1, DSL; ADSL networks which providing data rate up to $2 \mathrm{Gbps}$. The designed system in this paper is capable for high speed data rate transmission $20 \times 32 \mathrm{~GB} / \mathrm{s}(640 \mathrm{~GB} / \mathrm{s})$. It is observed that EDC significantly reduce BER by $1.0798 \mathrm{e}^{-010}, 1.1556 \mathrm{e}^{-011}, 1.2960 \mathrm{e}^{-010}$ and $8.8979 \mathrm{e}^{-009}$ at four different wavelengths $1550 \mathrm{~nm}, 1559.6 \mathrm{~nm}, 1562.8 \mathrm{~nm}$ and $1.574 .8 \mathrm{~nm}$ for NRZ modulation format for 64 subscribers for $20 \mathrm{~GB} / \mathrm{s}$ at $40 \mathrm{~km}$ fiber length respectively. Sharp increase in BER 2.6916 $\mathrm{e}^{-002}, 4.6519 \mathrm{e}^{-002}, 3.8804 \mathrm{e}^{-001}$ and $5.1570 \mathrm{e}^{-002}$ occurs if data rate increased up to $25 \mathrm{~GB} / \mathrm{s}$. The system is unstable if more number of subscribers accommodates and fiber length increased more than $40 \mathrm{~km}$.

\section{Acknowledgments}

I specially want to thanks to my research supervisor HOD of ECE department Assistant Prof. ANURAG SHARMA who were of indeed great help to me at every step and made me comfortable at my research work for his valuable help during the development of the research paper. Without his suggestion and timely help we would not have been able to complete our paper.I would like to place on record my deep sense of gratitude to Dr. K.K CHAWLA Campus Director of CTITR, Jalandhar India for his generous guidance, help and useful suggestions. I am extremely thankful to our Group Director Dr. MANOJ KUMAR, CT Group of Institutes, Jalandhar for providing me infrastructural facilities to work in, without which this work would not have been possible. Finally, my deepest gratitude goes to my family for their unflagging love and unconditional support throughout my life and my studies.

\section{References}

[1] R. Asif, M. Imtiaz, J. Yasemin and M. Nazir, "Performance enhanced down-stream signalling for next generation long-reach 10Gbit/s passive optical networks", Opt. - Int. J. Light Electron Opt., vol. 125, (2014), pp. 6017-6020. 
[2] A. Chenika, A. Temmar and O. Seddiki, "Transmission of $4 \times 40 / 10$ Gbps in a WDM-PON using NRZDQPSK/ASK modulation", Opt. - Int. J. Light Electron Opt., vol. 125, (2014), pp. 6296-6298.

[3] M. De Andrade, M. Maier, M. P. McGarry and M. Reisslein, "Passive optical network (PON) supported networking", Opt. Switch. Netw, vol. 14, (2014), pp. 1-10.

[4] M. A. Elmagzoub, A. B. Mohammad, R. Q. Shaddad and S. A. Al-Gailani, "Physical layer performance analysis of hybrid and stacked TDM-WDM 40G-PON for next generation PON", Opt. - Int. J. Light Electron Opt., vol. 125, (2014), pp. 6194-6197.

[5] H. Erkan, G. Ellinas, A. Hadjiantonis, R. Dorsinville and M. Ali, "Dynamic and fair resource allocation in a distributed ring-based WDM-PON architectures", Comput. Commun., vol. 36, (2013), pp.15591569.

[6] M. Fujiwara, H. Suzuki, N. Yoshimoto and K. Iwatsuki, "Loss budget expansion technique using gainsaturated SOA in WDM single-fiber loopback access networks", Opt. Fiber Technol., vol. 13, (2007), pp. 72-77.

[7] T. B. Gibbon, K. Prince, T. T. Pham, A. Tatarczak, C. Neumeyr and E. Rönneberg, "VCSEL transmission at $10 \mathrm{~Gb} / \mathrm{s}$ for $20 \mathrm{~km}$ single mode fiber WDM-PON without dispersion compensation or injection locking", Opt. Fiber Technol, vol. 17, (2011), pp. 41-45.

[8] B. Huang, Y. An, N. Chi, M. Xiong, H. Ou and W. Liu, "Combining DPSK and duobinary for the downstream in 40-Gb/s long-reach WDM-PONs", Opt. Fiber Technol., vol. 19, (2013), pp.179-184.

[9] R. Kaler and R. S. Kaler, "Simulation of Fiber to the Home at 10Gbit/s using GE-PON architecture", Opt. - Int. J. Light Electron Opt., vol. 122, (2011), pp. 1362-1366.

[10] I. Kartiwa, S.-M. Jung, M.-K. Hong and S.-K. Han, "20Gb/s WDM-OFDM-PON over 20-km single fiber uplink transmission using optical millimeter-wave signal seeding with rate adaptive bit-power loading", Opt. Fiber Technol., vol. 19, (2013), pp. 231-235.

[11] K. P. Kaur, R. Randhawa and R. S. Kaler, "Low cost architecture to integrate multiple PONs to a long reach spectrum sliced WDM network", Opt. - Int. J. Light Electron Opt., vol. 125, (2014), pp. 45134516.

[12] K. P. Kaur, R. Randhawa and R. S. Kaler, "Performance analysis of WDM-PON architecture using different receiver filters", Opt. - Int. J. Light Electron Opt., vol. 125, (2014), pp. 4742-4744.

[13] Y. Lu, Y. Wei, M. Hu, X. Zhou, Z. Qian and Q. Li, "Triple functional shared channel in WDM PON by orthogonal modulation and network coding", Opt. Commun., vol. 336, (2015), pp. 103-105.

[14] X. Ma, C. Gan and S. Deng, "A novel colorless WDM passive optical network delivering up/downstream signals and video broadcast signal simultaneously", Opt. Switch. Netw., vol. 10, (2013), pp. 100-105.

[15] Y. Qiao, Q. Li and Y. Ji, "400Gbps WDM transmission over short range with discrete multi-tone", Opt. - Int. J. Light Electron Opt, vol. 125, (2014), pp. 5850-5852.

[16] R. M. Mu, T. Yu, V. S. Grigoryan and C. R. Menyuk, "Dynamics of the chirped return-to-zero modulation format", J. Light. Technol., vol. 20, (2002), pp. 47-57.

[17] S. Prakash, D. Kumar, A. Sharma and R. Malhotra, "Performance Investigation of GE-PON Fiber To The Home Network Under Varying Data Rates and Users", published in Proceedings of International Conference: IMTC -2014, 3-4 June, CTIEMT, Jalandhar, pp. 156-159

[18] A. Sharma, M. Kumar, A. and S. Parkash, "Dynamics of Chirped RZ Modulation Format in GEPON Fiber to the Home ( FTTH ) Network", World Academy of Science, Engineering and Technology Electrical and Computer Engineering (WASET 2015.) vol. 2, no. 7, vol. 2, no. 7, p. 8535 